\title{
2020 BEST PIC II PAPER WINNER - Developing a Multi-Campus Model for REU \\ Sites
}

Dr. Pamela McLeod, Stanford University

Pamela McLeod is the Education \& Outreach Director and Diversity \& Inclusion Manager for the Engineering Research Center for Re-inventing the Nation's Urban Water Infrastructure (ReNUWIt) at Stanford University. Dr. McLeod earned M.S. and Ph.D. degrees in Civil \& Environmental Engineering from Stanford and a B.S. in Environmental Engineering from Manhattan College. Her professional interests include engineering education, collaborative community development, science communication, and integrating inclusive practices into engineering research enterprises.

Dr. Junko Munakata Marr, Colorado School of Mines

Prof. Richard G. Luthy, Stanford University 


\section{Developing a Multi-Campus Model for REU Sites}

\section{Dr. Pamela McLeod, ReNUWIt at Stanford University}

Pamela McLeod is the Education and Outreach Director and Diversity and Inclusion Manager for the Engineering Research Center for Re-inventing the Nation's Urban Water Infrastructure (ReNUWIt) at Stanford University. Dr. McLeod earned M.S. and Ph.D. degrees in Civil and Environmental Engineering from Stanford and a B.S. in Environmental Engineering from Manhattan College. Her professional interests include engineering education, collaborative community development, science communication, and integrating inclusive practices into engineering research enterprises.

\section{Dr. Junko Munakata Marr, Colorado School of Mines}

Dr. Munakata Marr is a Professor of Civil and Environmental Engineering at the Colorado School of Mines in Golden, Colorado. She earned her BS degree in Chemical Engineering from the California Institute of Technology and her MS and PhD degrees in Civil Engineering from Stanford University. Her research and teaching interests revolve primarily around microorganisms in engineered environmental systems, including biological wastewater treatment and methanogenesis from unconventional sources. She has nearly 20 years of experience in bioremediation. Other interests include sustainable water infrastructure, increasing diversity among STEM students and faculty, and sustainable community development.

\section{Prof. Richard G Luthy, Stanford University}

Silas H. Palmer Professor, Department of Civil and Environmental Engineering, Stanford University, Stanford, CA 


\title{
Developing a Multi-Campus Model for REU Sites
}

\begin{abstract}
Studies suggest Research Experiences for Undergraduates (REU) programs promote persistence in STEM fields, increased interest in graduate school, and development of identity as a researcher for REU participants. While most REU programs operate on a single campus, a growing number offer participants the opportunity to engage in research at geographically distributed campuses united around a common theme. Though logistically challenging, such a program can expand participants' networks while maintaining a sense of cohort and community, which is important for researcher identity development. The current study investigates the outcomes of an REU Site run across four campuses within the National Science Foundation (NSF)-funded Engineering Research Center (ERC) for Re-inventing the Nation's Urban Water Infrastructure (ReNUWIt). Participants to date have been $69 \%$ female and 39\% from historically underrepresented racial or ethnic groups. Outcomes include participant skill-building, development of researcher identity, pursuit of graduate school, and pursuit of careers in STEM. Assessments include pre- and post-surveys (quantitative and qualitative), as well as longitudinal tracking of participants ( $\mathrm{n}=97$ over 7 years). Assessment results suggest this multi-campus site achieves participant-level and program-level impacts commensurate with those attained by single-campus REU Sites.
\end{abstract}

\section{Introduction}

Engaging undergraduates in authentic science and engineering research experiences is widely accepted as a promising practice for promoting persistence in the discipline [1], increasing student interest in graduate school [2], and developing a student's identity as a researcher [1]. The U.S. National Science Foundation (NSF) is a large supporter of such experiences through its Research Experience for Undergraduates (REU) Site and Supplements Program. Almost 150 REU Site Programs are currently funded in Engineering.

Most REU Sites are based at a single institution. This traditional model for REU Sites typically involves 8-12 participants per summer, housed in close proximity on campus, engaged in research projects united by a common theme. Having a unifying theme and developing strong camaraderie are two aspects deemed critical to a successful REU program [3].

A small but growing number of summer REU programs have operated as a single program across multiple, geographically dispersed institutions. Multi-campus Sites offer access to a broader network of researchers, exposure to multiple institutions, and immersion in an extended research community working towards common goals. However, operating a Site across geographically distant universities introduces logistical and programmatic challenges that need to be addressed to ensure a high-quality program.

Several examples of multi-campus REU programs appear in the literature (e.g., Theoretically Interesting Molecules (TIM) Consortium [4], National Nanotechnology Infrastructure Network (NNIN) [5], Pacific Earthquake Engineering Research Center (PEER) [6], Rosetta Commons [7], and Engineering Research Center for Wireless Integrated MicroSystems (WIMS ERC)) [8]. A 
prior study of the Rosetta Commons, a multi-campus computational biology REU, found it matched outcomes for community, scientific identity, scientific self-efficacy, and intention to pursue a science research-related career when compared to two single-campus life sciences REU programs [7]. While this result is promising, a general knowledge gap remains regarding best practices for implementing multi-campus Sites and comprehensive evaluation of how their outcomes compare to those of traditional, single-institution programs.

This paper describes a multi-campus REU program run across the four partner campuses within the NSF Engineering Research Center (ERC) for Re-inventing the Nation's Urban Water Infrastructure (ReNUWIt): Stanford University, Colorado School of Mines (Mines), New Mexico State University (NMSU), and the University of California at Berkeley. ReNUWIt focuses on water in the American West through fundamental investigations and applied research to create a suite of successful water management options and decision-making tools. Our research aims include incorporating resource recovery and energy production into engineered water systems; engineering natural systems to improve water quantity, water quality, and habitat; and overcoming barriers to adopting new urban water management strategies. The ReNUWIt REU program was supported through a combination of funding from the ERC's base budget and two NSF REU Site awards (2013-2016 and 2017-2020).

\section{Program objectives}

The program-level objectives of the ReNUWIt REU are (O1) to provide participating students with hands-on research experiences using cross-disciplinary, systems-level approaches, that directly address the design of urban water infrastructure and key knowledge gaps in water science/engineering, and $(\mathrm{O} 2)$ to increase undergraduate students' interests in pursuing advanced degrees in water science/engineering, with a particular emphasis on women and minorities.

In addition to the program-level objectives, we identified five student-level outcomes that provide a framework for the assessment plan. We proposed that through participating in this REU, students would: (S1) conduct independent research in water science or engineering; (S2) gain an understanding of urban water infrastructure challenges and the ERC's systems-level approach; (S3) experience the enthusiasm and passion our ERC research team has for water science and engineering; (S4) express increased interest in pursuing graduate degrees in engineering and science; (S5) demonstrate increased proficiency and facility in technical speaking and writing.

\section{Program structure}

A typical timetable for our REU is displayed in Table 1, with the application window opening in October and the program ending in mid-August. Program activities are centrally managed by the Program Director.

This REU Program supported between 8 and 16 participants per summer from 2013 through 2019. Participants joined existing research teams working on projects related to water and wastewater science and engineering. Each participant was paired with one to two primary graduate student / postdoctoral researcher / staff researcher mentors, under the guidance of a 
faculty advisor (PI). Participants were expected to dedicate approximately 40 hours per week to their research. During mentor training we emphasized the importance of participants increasing their independence over the course of the summer, and encouraged mentors to consider their activities accordingly. A gallery of program alumni, project titles, and project deliverables can be found on the program website (http://renuwit.org/education/reu-program/previous-reus/).

Table 1. Annual program cycle for ReNUWIt REU Program.

\begin{tabular}{|c|c|}
\hline Month & REU program activity \\
\hline October & Application window opens. Recruitment efforts begin. \\
\hline January & Confirm projects and PI/mentor team needs. \\
\hline February & $\begin{array}{l}\text { Application window closes (February } 10) \text {. } \\
\text { Initial application screening. PI/mentor teams select top choice candidates. } \\
\text { Offer process begins. }\end{array}$ \\
\hline March & $\begin{array}{l}\text { Offer process continues until all positions are filled. } \\
\text { Housing placements are confirmed on all campuses. }\end{array}$ \\
\hline April & $\begin{array}{l}\mathrm{PI} / \text { mentor teams send introductory emails and background reading to REUs. } \\
\text { Program travel is arranged. }\end{array}$ \\
\hline May & $\begin{array}{l}\text { Mentor orientation and training occurs via videoconference. } \\
\text { Program begins at Mines and NMSU. Pre-program survey administered. }\end{array}$ \\
\hline June & $\begin{array}{l}\text { Program begins at Berkeley and Stanford. Pre-program survey administered. } \\
\text { Participants convene for all-REU Meeting. }\end{array}$ \\
\hline July & Program ends at Mines and NMSU. Post-program survey administered. \\
\hline August & Program ends at Berkeley and Stanford. Post-program survey administered. \\
\hline
\end{tabular}

Our Site placed a strong emphasis on communication. As noted in Table 2, REU participants delivered a series of oral presentations throughout the summer: a two-minute project introduction, five-minute mid-program presentation, and ten-minute final presentation. Participants received compiled, anonymous peer feedback and had oral communication consultation sessions following their five-minute presentations. Participants also prepared a twopage extended abstract and one or two summary slides as final program deliverables. Beginning in 2017, participants submitted draft abstracts to an ERC faculty member during Week 7 for constructive feedback.

The 9 to 10-week program was offset at each campus, based on the different academic calendars and associated availability of on-campus housing. Though their start and end dates differed, the REUs followed the same general program timeline shown in Table 2.

Given the importance of the cohort in achieving positive outcomes [1], we prioritized community development in REU programming. To foster community cohesion among our REU participants, we (1) convened for weekly videoconference meetings, (2) held an All-REU Meeting at Stanford during the first few weeks of the program, (3) sent a weekly newsletter to participants and mentors, and (4) encouraged participants to connect via social media. The REU Program 
Director also visited REUs at each campus at least once during the summer, to further increase cohesion and strengthen relationships.

Table 2. Typical REU program timeline with deliverables and associated venues for groups with different start times on different campuses.

\begin{tabular}{lccc}
\hline Deliverable & Week & Mines \& NMSU & Berkeley \& Stanford \\
\hline Two-minute presentation & 2 or 3 & videoconference & all-REU meeting \\
Five-minute presentation & 4 or 5 & all-REU meeting & videoconference \\
Draft abstract & 7 & \multicolumn{2}{c}{ online } \\
Ten-minute presentation & 9 & \multicolumn{2}{c}{ videoconference } \\
Abstract, summary slide, web photo & 9 & \multicolumn{2}{c}{ online } \\
\hline
\end{tabular}

Weekly videoconference meetings. REUs met in a central location on each campus each week to connect across campuses via Zoom. Meeting format varied by week, and included participant presentations, REU alumni panels, guest speakers, and journal club discussions.

All-REU Meeting. Near the beginning of the program, REUs from all campuses traveled to Stanford, ReNUWIt's lead institution, for an in-person meeting. The meeting spanned two days in 2013; based on participant feedback it was extended to three days in subsequent summers. Programming included a topical discussion with ReNUWIt's Director, professional development (e.g., graduate school preparation, data visualization, etc.), and cohort-building activities. The all-REU meeting culminated in a half-day research symposium during which our participants delivered either their five-minute mid-program presentations or two-minute project introductions, depending on their REU home campus.

Weekly newsletter. Each week, the Program Director produced a newsletter that was sent to all participants and mentors/PIs. Participants and mentors were encouraged to submit photos of both research and social activities for inclusion in the newsletter. In addition to these photos and short blurbs, the newsletter included upcoming program reminders and a "Water in the News" section featuring recent ReNUWIt research publications and water-related popular articles.

Social media. The Program Director encouraged participants to connect via social media to maintain communication across campuses. While the 2013-2015 cohorts generally favored Facebook, more recent cohorts have moved to Snapchat, WhatsApp, and text groups.

In addition to cross-campus cohort development, efforts were made to foster community among the smaller groups of participants on each campus. When possible, we also connected students with other co-located summer research programs on each campus. This allowed for access to a larger local community of peers in addition to those within our program. In some cases, these connections allowed for shared campus orientations, seminars, and organized social events.

\section{Student recruitment and selection}

The REU Site was advertised via typical channels, including a program website, flyer circulated to appropriate listservs and faculty connections, and social media. A single application portal was used for the Site, with applicants selecting the campuses for which they would like to be 
considered. Applications were considered complete if they included an application form, personal statement, unofficial transcript(s), and at least one letter of recommendation.

Applicant review occurred in two phases: initial screening and PI/mentor review. During the initial screening, personal statements and recommendation letters were read by the screening committee and scored via a shared rubric. The screening committee was comprised of the REU Program Director and graduate students and postdoctoral researchers within ReNUWIt. Efforts were made to ensure that each application was read by the REU Program Director and at least one other individual on the committee. At the end of the initial screening, each application was binned as "Yes," "Maybe," or "No."

Following the initial screening, the REU Program Director curated small batches of approximately five applications from the "Yes" and "Maybe" bins to send to each PI/mentor team. Applicants were matched to projects based on a number of applicant-specific factors including ranked research interests, course background, research experience, and campuses of interest; and project-specific requirements including desired course background and level of prior research experience. PI/mentor teams were reminded of the program's goals to achieve a diverse cohort, with more than $50 \%$ of participants coming from primarily undergraduate institutions. Each PI/mentor team reviewed their small batch of applications and selected their top two choices. The REU Program Director then sent an offer to the selected candidate.

For summers 2014-2019, we received an average of 200 completed applications per year. We received fewer - 66 - in 2013, likely due to the compressed recruitment timeframe in the first year of our first REU Site award. Figure 1 shows selected demographics for our applicant pools and participating students.
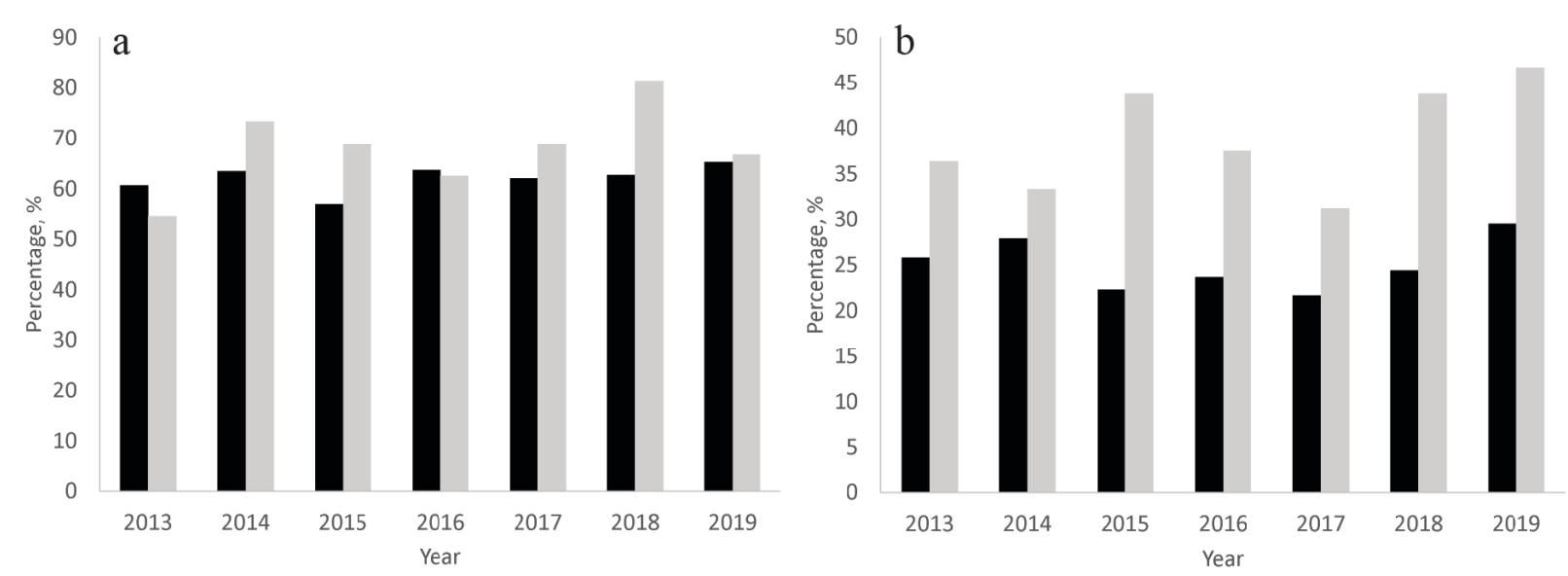

Figure 1. Percentage of applicants (black bars) and participants (gray bars) who self-identified as (a) female or (b) underrepresented minority (African American/Black, Native American/Native Alaskan, Pacific Islander/Native Hawaiian, Hispanx/Latinx/Chicanx, and/or mixed race including one or more of these demographics).

Across all years, the applicant pools (means \pm standard deviation) included $62.1 \% \pm 2.7 \%$ female and $25.0 \% \pm 2.9 \%$ URM applicants, where URM is defined as African American, Native American, Pacific Islander, Hispanx/Latinx/Chicanx, and/or mixed race including one or more of 
these demographics. Over seven summers (2013-2019), 97 students participated in the ReNUWIt REU. Of those, 67 (69\%) were female and 38 (39\%) identified as URM. These demographics compare favorably with other environmental engineering REU Sites for which published data are readily available [9-12], and suggest our REU has been relatively successful in recruiting women and underrepresented minorities.

\section{Program assessment}

IRB-approved pre- and post-surveys were administered to participants each summer to assess participant outcomes and identify areas for improvement year-to-year. The surveys included a combination of Likert-scale and open-ended questions. Mentors and PIs were also surveyed postprogram as an element of formative assessment. REU program alumni continue to be tracked longitudinally to determine longer-term education and career outcomes. Program staff reviewed responses on an annual basis to determine opportunities for program improvement. An external evaluator prepared assessment reports based on the pre- and post-survey data over two periods 2013-2016 [13] and 2017-2018 [14]. Assessment results from the 2019 program have not yet been analyzed. The external evaluator will also assist in assessing the program's legacy.

Selected assessment results and discussion are presented in this section, discussed in comparison with several single-campus REU Sites in similar fields for which assessment data are available in the literature: the Clarkson REU Site Program in Environmental Science and Engineering [9], the REU Site on Interdisciplinary Water Science and Engineering at Virginia Tech [10], the REU Site in Environmental Engineering at University of Colorado, Boulder [12], and the Chemistry Chemical Engineering: the Bonds Between Us REU Site at Mississippi State University [15].

During 2013-2016, 50 students participated in our REU program. In that period, 49 participants completed the pre-survey and 46 completed the post-survey. During 2017-2018, 32 students participated in our REU program. In that period, 29 participants completed the pre-survey and 26 completed the post-survey. The high level of survey participation suggests that assessment results provide a robust snapshot of the student experience in our REU Site. When appropriate, paired and independent t-tests were used to compare pre- and post-survey results.

Changes in perceived competency in research-related skills were determined by asking students to rate their confidence in their ability to perform basic tasks related to the research process (Table 3). Students' reported confidence in research-related skills increased on almost every item between the pre- and post-program surveys. Students in the 2013-2016 cohort reported the largest increase in confidence in their ability to integrate relevant published data into their research projects. Students in the 2017-18 cohort reported the largest confidence increases in their ability to plan experiments, integrate relevant published data into their research projects, and connecting new data to old.

Direct, quantitative comparisons of research skills gains across programs are challenging due to evaluators' use of different methods to assess such gains. While many employ self-reported participant pre- and post-program surveys, the various instruments use different wording and/or scales. Our results are similar to the three comparison single-campus environmental engineering and chemical engineering REUs that reported research skill assessment data $[10,12,15]$ in that 
all observed modest, often statistically significant, increases in student confidence regarding their research skills.

Table 3. Changes in students' confidence in research-related skills (mean \pm sd). Scale: $1=$ Not at all confident; $2=$ Somewhat confident; $3=$ Confident; $4=$ Very confident. Significance: $*=\mathrm{p}<$ $0.05, * *=\mathrm{p}<0.01, \mathrm{NS}=$ Not significant.

\begin{tabular}{|c|c|c|c|c|c|c|}
\hline \multirow[b]{2}{*}{ Survey Statement } & \multicolumn{3}{|c|}{ 2013-2016 } & \multicolumn{3}{|c|}{$2017-2018$} \\
\hline & $\begin{array}{c}\text { Pre- } \\
\text { Program }\end{array}$ & $\begin{array}{c}\text { Post- } \\
\text { Program }\end{array}$ & Sig. & $\begin{array}{c}\text { Pre- } \\
\text { Program }\end{array}$ & $\begin{array}{l}\text { Post- } \\
\text { Program }\end{array}$ & Sig. \\
\hline Keeping a lab notebook & $3.30 \pm 0.823$ & $3.20 \pm 0.694$ & NS & $3.10 \pm 0.939$ & $3.38 \pm 0.852$ & NS \\
\hline Conducting literature searches & $2.89 \pm 0.868$ & $3.09 \pm 0.694$ & NS & $3.00 \pm 0.655$ & $3.23 \pm 0.908$ & NS \\
\hline Organizing information & $3.45 \pm 0.589$ & $3.46 \pm 0.546$ & NS & $3.38 \pm 0.723$ & $3.61 \pm 0.571$ & NS \\
\hline Planning experiments & $2.40 \pm 0.760$ & $2.91 \pm 0.772$ & $* *$ & $2.45 \pm 0.827$ & $3.08 \pm 0.744$ & $* *$ \\
\hline $\begin{array}{l}\text { Integrating relevant published data into your } \\
\text { research project }\end{array}$ & $2.50 \pm 0.849$ & $3.07 \pm 0.772$ & $* *$ & $2.59 \pm 0.867$ & $3.19 \pm 0.634$ & $* *$ \\
\hline Critically reading primary journal articles & $2.64 \pm 0.892$ & $3.02 \pm 0.621$ & $*$ & $2.76 \pm 0.786$ & $3.23 \pm 0.765$ & $* *$ \\
\hline Identifying relevant questions for inquiry & $2.61 \pm 0.993$ & $3.02 \pm 0.621$ & $*$ & $2.52 \pm 0.738$ & $3.19 \pm 0.694$ & $*$ \\
\hline Interpreting research results & $2.64 \pm 0.838$ & $2.89 \pm 0.567$ & $* *$ & $2.72 \pm 0.751$ & $3.19 \pm 0.634$ & $*$ \\
\hline Connecting new data to old & $2.75 \pm 0.719$ & $2.98 \pm 0.745$ & $*$ & $2.75 \pm 0.645$ & $3.35 \pm 0.629$ & $* *$ \\
\hline Communicating ideas to team members & $3.23 \pm 0.605$ & $3.39 \pm 0.614$ & NS & $3.07 \pm 0.704$ & $3.46 \pm 0.647$ & NS \\
\hline Preparing a scientific presentation & $2.86 \pm 0.889$ & $3.26 \pm 0.535$ & $* *$ & $2.90 \pm 0.673$ & $3.46 \pm 0.582$ & $*$ \\
\hline Delivering a scientific presentation & $2.84 \pm 0.871$ & $3.13 \pm 0.582$ & $*$ & $2.83 \pm 0.805$ & $3.27 \pm 0.667$ & NS \\
\hline Writing a paper suitable for publication & $1.93 \pm 0.828$ & $2.39 \pm 0.802$ & $* *$ & $2.00 \pm 0.845$ & $2.58 \pm 0.809$ & * \\
\hline
\end{tabular}

Prior studies suggest that development of identity as a scientist/researcher $[16,17]$ is a predictor of students' likelihood to persist in STEM fields. As shown in Table 4, students were significantly more likely to identify as a water researcher, feel confident in their ability to work in a research lab, and feel confident about their ability to access experts in the water field after participating in the ReNUWIt REU. We postulate that the multi-campus nature of this REU was a contributing factor to students' feeling of increased connection to a larger network of water experts.

Table 4. Changes in students' identity and confidence in abilities regarding water research (mean $\pm \mathrm{sd}$ ). Scale: $1=$ Strongly Disagree, $2=$ Disagree, $3=$ Neither Agree nor Disagree, $4=$ Agree, 5 $=$ Strongly Agree. Significance: $*=p<0.05, * *=p<0.01$

\begin{tabular}{|c|c|c|c|c|c|c|}
\hline \multirow[b]{2}{*}{ Survey Statement } & \multicolumn{3}{|c|}{ 2013-2016 } & \multicolumn{3}{|c|}{$2017-2018$} \\
\hline & $\begin{array}{c}\text { Pre- } \\
\text { Program }\end{array}$ & $\begin{array}{c}\text { Post- } \\
\text { Program }\end{array}$ & Sig. & $\begin{array}{c}\text { Pre- } \\
\text { Program }\end{array}$ & $\begin{array}{c}\text { Post- } \\
\text { Program }\end{array}$ & Sig. \\
\hline I think of myself as a water researcher. & $3.89 \pm 0.722$ & $4.09 \pm 0.694$ & $*$ & $3.71 \pm 0.810$ & $4.12 \pm 0.816$ & $* *$ \\
\hline $\begin{array}{l}\text { I am confident in my ability to work in a } \\
\text { research lab. }\end{array}$ & $4.00 \pm 0.715$ & $4.37 \pm 0.610$ & ** & $4.04 \pm 0.637$ & $4.58 \pm 0.578$ & $* *$ \\
\hline $\begin{array}{l}\text { I am confident about my ability to access experts } \\
\text { in the water field. }\end{array}$ & $3.34 \pm 0.987$ & $3.96 \pm 0.665$ & $* *$ & $3.11 \pm 0.956$ & $4.23 \pm 0.612$ & $* *$ \\
\hline
\end{tabular}

Changes in students' future goals specific to water research were probed through their level of agreement with the statements "I am going to pursue graduate studies in water research" and "I 
am going to pursue a career in water research" (5-point Likert scale) on the pre- and postsurveys, as shown in Table 5. For both the 2013-2016 and 2017-2018 cohorts, the percentage of participants agreeing or strongly agreeing with the statement "I am going to pursue graduate studies in water research" increased between the pre- and post-program surveys. The mean response to this statement also increased from pre-survey to post-survey, though this increase was only statistically significant $(\mathrm{p}<0.05)$ for the 2013-2016 cohort. For both cohorts, the percentage of participants agreeing or strongly agreeing with the statement "I am going to pursue a career in water research" also increased slightly between the pre- and post-program surveys. The mean response to this statement also increased from pre-survey to post-survey, though this increase was only statistically significant $(p<0.01)$ for the $2017-2018$ cohort. Additional analyses comparing these items by gender and race/ethnicity did not reveal any statistically significant differences.

Similarly small increases in intent to pursue graduate degrees were reported for the four comparison single-campus REUs [9, 10, 12, 15]. The Clarkson REU reported a decrease in intention to pursue a research career between pre- and post-program surveys [9]. The other three comparison single-campus REUs did not report assessing career intent via pre- and post-surveys, though the Water REU at Virginia Tech found that $75 \%$ of alumni survey respondents were pursuing or likely to pursue a research career in engineering/science [10].

Table 5. Changes in students' future goals specific to water research (mean \pm sd). Scale: $1=$ Strongly Disagree, $2=$ Disagree, $3=$ Neither Agree nor Disagree, $4=$ Agree, $5=$ Strongly Agree . Significance: NS $=$ Not significant, $*=p<0.05, * *=p<0.01$

\begin{tabular}{lccc|ccc}
\hline \multicolumn{1}{c}{ Survey Statement } & $\begin{array}{c}\text { Pre- } \\
\text { Program }\end{array}$ & $\begin{array}{c}\text { 2013-2016 } \\
\text { Post- } \\
\text { Program }\end{array}$ & Sig. & $\begin{array}{c}\text { Pre- } \\
\text { Program }\end{array}$ & $\begin{array}{c}\text { 2017-2018 } \\
\text { Post- } \\
\text { Program }\end{array}$ & \begin{tabular}{l} 
Sig. \\
\hline $\begin{array}{l}\text { I am going to pursue graduate studies in water } \\
\text { research. }\end{array}$
\end{tabular} \\
$\begin{array}{l}\text { I am going to pursue a career in water } \\
\text { research. }\end{array}$ & $4.77 \pm 0.937$ & $3.98 \pm 0.954$ & $*$ & $3.71 \pm 0.763$ & $3.84 \pm 1.344$ & $\mathrm{NS}$ \\
\hline
\end{tabular}

On the post-program survey, participants rated their summer research experience on a 5-point scale from poor to excellent. Across both periods, participants rated their overall summer research experience very highly, with $92 \%$ of respondents characterizing it as very good $(22.2 \%)$ or excellent (69.4\%), with mean ratings of $4.54 \pm 0.721$ in 2013-2016 and 4.65 \pm 0.745 in 20172018. Our result is similar to those reported by the two comparison single-campus REUs that assessed overall participant experience $[9,15]$.

\section{Longitudinal tracking}

Longitudinal tracking of alumni provides further metrics to assess overall program outcomes. The Program Director maintains semi-regular contact with program alumni via email, social media, and an annual alumni newsletter. Contact has been maintained with all but two of our alumni. Of the 76 Site alumni who have already graduated from their undergraduate institutions, $48(63 \%)$ have gone on to pursue graduate degrees in water science and engineering. Sixteen have pursued their graduate degrees at ReNUWIt campuses: ten at their REU host institution and six at another ReNUWIt partner institution. Three have pursued advanced degrees in health care 
professions. A few others plan to start graduate school in Fall 2020. Of the 48 who went on to pursue graduate degrees in water science and engineering, $34(71 \%)$ were female and $18(38 \%)$ were URM. No statistical differences in the likelihood to attend graduate school were observed based on gender or race/ethnicity. Our legacy assessment will further characterize the education and career trajectories of our program alumni, as well as their retrospective reflections regarding the impact participating in our program had on their education and career choices.

Alumni tracking for the three comparison environmental engineering REU Programs found that over $60 \%$ of participants of the Clarkson REU attended graduate or professional school [9], approximately $60 \%$ of the CU-Boulder Program's participants continued on to graduate studies, and nearly $50 \%$ of participants of the Water REU at Virginia Tech were attending or had attended graduate school [10]. Thus, our outcomes for students attending graduate school are similar to single-campus REUs in the same discipline.

\section{Challenges and opportunities}

Operating an REU Site across multiple campuses presents a number of logistical challenges, as others have described $[5,6,8,18]$. Program staff must navigate the academic calendars, residential housing offices, and payroll setup requirements on each campus. The importance of dedicated staff and administrative support cannot be overstated. In our case, the Program Director and an administrative associate at Stanford oversaw overall program scheduling, arranged participant travel, and worked with appropriate faculty and offices on all four ReNUWIt campuses to secure on-campus housing and arrange stipend payments. Even with this oversight and continuity, issues regarding payroll setup and ID cards arose some summers on individual campuses, and were sometimes identified as program challenges by participants on their post-program surveys.

As described earlier in this paper, the relatively small number of participants on each campus presents the challenge of establishing local community and cohort. While we worked to connect participants with co-located programs, challenges arose when other programs lost funding, schools changed their summer seminar setup, and/or local undergraduates already had existing social networks.

Another unique programmatic challenge for this Site was the need to offset program start and end dates due to the different academic calendars on each campus. In most summers a two to three week gap occurred between the earliest- and latest-starting campuses. In many multicampus REU sites the group convenes in person once at the beginning of the program and perhaps again at the end $[4,6,7]$. This was not possible for our Site given the schedule offset. However, the offset did allow an element of peer-to-peer mentoring in that the earlier-starting REUs were (albeit, slightly) more experienced than the later-starting REUs.

The multi-campus REU model also provides some unique opportunities to program participants. Our program allowed students to pursue related research projects unique to diverse geographic locations and universities, and broadened the range of research available to them. It afforded students glimpses into the research environments and culture at more than one institution; students on three campuses traveled to the lead institution during the all-REU meeting, and also 
learned about the four partner campuses throughout the program. While ReNUWIt includes public and private institutions and a Hispanic-serving Institution, additional institution types (e.g., primarily undergraduate, other minority-serving institutions) may broaden the students' experience of various research environments.

Students also gained access to a multi-campus network of water experts. As stated earlier in this paper, of the 16 alumni who pursued or are pursuing graduate school at institutions within our ERC, ten returned to their host institution for graduate school, while six enrolled at a ReNUWIt partner institution. ReNUWIt REU experiences thus facilitated graduate school pathways across our four campuses.

\section{Conclusion}

While direct, quantitative comparisons among programs are challenging due to differences in assessment approaches and relatively small amount of data in the literature, our results to date strongly suggest that outcomes from our multi-campus REU are commensurate with those from single-campus Sites. Participants in our REU reported gains in research skills and confidence at similar levels to those in single-campus REUs in our discipline. Their confidence in conducting research and accessing experts in the field increased significantly, as did their identification as a water researcher. Their intent to pursue graduate school and research careers in the water sector remained steady or increased after participating in the program, similar to the single-campus comparison Sites. Thus, when logistical challenges are carefully addressed, multi-campus REU Sites appear to have the potential to achieve meaningful and positive student- and programspecific outcomes.

\section{Acknowledgments}

This work is supported by the National Science Foundation through the Engineering Research Center for Re-inventing the Nation's Urban Water Infrastructure (ReNUWIt) and the ReNUWIt REU Site (EEC-1028968, EEC- 1262655, and EEC-1559984).

\section{References}

[1] M. J. Graham, J. Frederick, A. Byars-Winston, A.-B. Hunter, and J. Handelsman, "Increasing Persistence of College Students in STEM," Science, vol. 341, no. 6153, p. 1455, 2013, doi: 10.1126/science.1240487.

[2] S. H. Russell, M. P. Hancock, and J. McCullough, "Benefits of Undergraduate Research Experiences," Science, vol. 316, no. 5824, pp. 548-549, 2007, doi:

10.1126/science.1140384.

[3] N. S. Foundation, "Research experiences for undergraduates (REU) supplements and sites: Program solicitation NSF 19-582," ed. Washington, D.C.: National Science Foundation, 2019.

[4] K. C. Russell and S. M. Biros, "The TIM Consortium: A Dispersed REU Site at Primarily Undergraduate Institutes," in Best Practices for Chemistry REU Programs, vol. 1295, (ACS Symposium Series, no. 1295): American Chemical Society, 2018, ch. 5, pp. 59-71. 
[5] N. Healy and L. Rathbun, "Research Experience for Undergraduates in Nanotechnology: Analysis of Participants 1997-2007," presented at the American Society for Engineering Education, 2008.

[6] H. Faison et al., "Preparing undergraduates for success through a multi-disciplinary, multi-campus research internship program focused on earthquake resiliency," 2012.

[7] R. F. Alford, A. Leaver-Fay, L. Gonzales, E. L. Dolan, and J. J. Gray, "A cyber-linked undergraduate research experience in computational biomolecular structure prediction and design," PLOS Computational Biology, vol. 13, no. 12, p. e1005837, 2017, doi: 10.1371/journal.pcbi.1005837.

[8] L. McAfee Jr, "Multi-Site Undergraduate Research Program Challenges to Benefits," presented at the International Conference on Engineering Education, Budapest, Hungary, 2008.

[9] S. J. Grimberg, T. A. Langen, L. D. Compeau, and S. E. Powers, "A Theme-Based Seminar on Environmental Sustainability Improves Participant Satisfaction in an Undergraduate Summer Research Program," Journal of Engineering Education, vol. 97, no. 1, pp. 95103, 2008, doi: 10.1002/j.2168-9830.2008.tb00957.x.

[10] D. Basu, V. Lohani, and J. Muffo, "Analysis of undergraduate research experiences in an interdisciplinary water science and engineering program," International Journal of Engineering Education, vol. 34, no. 1, pp. 155-170, 2018.

[11] R. B. Angela, "Student Learning Outcomes from an Environmental Engineering Summer Research Program," San Antonio, Texas, 2012/06/10, 2012. [Online]. Available: https://peer.asee.org/21943.

[12] A. R. Bielefeldt, "Learning Outcomes from an Environmental Engineering Summer Research Program," presented at the American Society for Engineering Education, San Antonio, TX, 2012.

[13] M. Kemis, "REU Program Summers 2013-2016 Evaluation Report," 2017.

[14] M. Kemis, "REU Program Summers 2017-2018 Evaluation Report," 2019.

[15] A. Minerick, "Outcomes of a Novel REU Site in Chemistry \& Chemical Engineering," presented at the American Society for Engineering Education, Pittsburgh, PA, 2008.

[16] M. M. Chemers, E. L. Zurbriggen, M. Syed, B. K. Goza, and S. Bearman, "The Role of Efficacy and Identity in Science Career Commitment Among Underrepresented Minority Students," Journal of Social Issues, vol. 67, no. 3, pp. 469-491, 2011, doi: 10.1111/j.15404560.2011.01710.x.

[17] H. Thiry, S. L. Laursen, and A.-B. Hunter, "What Experiences Help Students Become Scientists? A Comparative Study of Research and other Sources of Personal and Professional Gains for STEM Undergraduates," The Journal of Higher Education, vol. 82, no. 4, pp. 357-388, 2011/07/01 2011, doi: 10.1080/00221546.2011.11777209.

[18] L. McAfee Jr, "Multi-Site Undergraduate Research Program Challenges to Benefits." 